\title{
¿CÓMO SE COMPORTA ANDALUCÍA EN LA GLOBALIZACIÓN DEL SIGLO XXI?
}

\author{
Manuel J. Marchena Gómez \\ Enrique Hernández Martínez \\ Departamento de Geografía Física y Análisis Geográfico Regional. \\ Universidad de Sevilla \\ mmarchena@us.es, ehernandez5@us.es
}

\section{RESUMEN}

Después de tres décadas de autogobierno, y tras ser la región europea que más fondos comunitarios ha recibido, es una evidencia que Andalucía no ha convergido con el resto de regiones europeas, y continua en posiciones de retraso relativo. Este artículo plantea la necesidad de trascender una explicación "exógena" de esta situación, y vuelve la mirada tanto hacia el carácter extractivo y oligárquico de las élites andaluzas, en todas sus modalidades. Se propone tanto un cambio del modelo productivo y especialización en la globalización, como un cambio en las condiciones institucionales, de mayor inclusividad y competitividad empresarial.

Palabras clave: Andalucía, desarrollo regional, globalización, élites extractivas.

\section{ABSTRACT}

After three decades of self-government and having become the European region that has received the most community funds, Andalusia has evidently not converged with the other European regions and remains in positions that lag relatively behind. This article poses the need to move beyond an 'exogenous' explanation for this situation and rather looks at the extractive and oligarchic nature of the Andalusian elites, in all respective modalities. A change of production model and specialisation in globalisation is proposed along with a change in institutional conditions to foster more business competitiveness and inclusion.

Keywords: Andalusia, regional development, globalisation, extractive elites.

Fecha de recepción: noviembre 2015.

Fecha de aceptación: marzo 2016. 


\section{ARGUMENTOS INTRODUCTORIOS}

Mundialización y Globalización son respectivamente un galicismo y un anglicismo; según la cultura científica por la que uno se deje influenciar. Pero habitualmente son utilizados indistintamente, pese al éxito notorio en el común del concepto globalización, por su procedencia anglosajona y, sobre todo, norteamericana (Retaille, -dir.-, 2010). La Real Academia de la Lengua ha sido renuente a introducir estos barbarismos en el Diccionario, pero en el avance de su vigésimo tercera edición, nos define mundialización como la "acción y efecto de mundializar", es decir, "de hacer algo que alcance una dimensión mundial". Por tanto, esta acepción se aproxima más a una expresión espacial o geográfica de la cosa. Mientras que cuando se aborda la globalización se apunta claramente a los hechos económicos: "tendencia de los mercados y de las empresas a extenderse alcanzando una dimensión mundial que sobrepasa las fronteras nacionales” (Azcarate y Montesa, -eds-, 2011).

Por tanto, existiría un proceso histórico de mundialización del que Andalucía sería fehaciente actor desde 1492 (Pérez-Mallaina, 2010). Seguramente, el momento clave para reconocer dicho concepto, pudo ser el reparto casi hemisférico del Nuevo Mundo sobre la base de un meridiano de delimitación (Este/Oeste) por el Tratado de Tordesillas (1494), entre España y Portugal (Boorstin, 2000). Proceso de Mundialización Geográfica (Levy, -dir.-, 2008) que se cierra desde los años ochenta del siglo XX, con la globalización económica, donde Andalucía se comporta como secularmente ha venido haciendo: semiperiféricamente (véase figura1), es decir, como periferia del Centro (Alburquerque, 2008). Con tres aspectos estructurales en el cambio de siglo: la revolución tecnológica y su aplicación económica en finanzas y tráfico de mercancías transnacionales e internacionales; la apertura comercial y la caída de barreras arancelarias; y el paso de una economía real a una economía financiera, o mejor, el creciente peso e influencia de la economía financiera sobre la economía real (Gruzinski, 2010).

Otra cosa es la interpretación política e ideológica de estos hechos que parecen incontestables (Sokol, 2011). Por ejemplo, acudiendo al fácil, y por tanto inexacto, maniqueísmo entre conservadores y progresistas, para otros de Liberales vs. Socialistas (Marchena, 2015). Los primeros apuntan a las bondades de la economía global (Friedman, 2005), de la transmisión del progreso entre el mundo desarrollado y el subdesarrollado, de los valores del librecambismo y el mercado como medios para el bienestar etc. Mientras que desde una visión progresista (léase por ejemplo a Harvey, 2102 o Ramonet, 2011 o Sassen, 2009), se critica la homogeneización occidental de la globalización, la asimetría de los beneficios de la misma según se hallen los actores en el Norte o el Sur económico, en general, el triunfo de los mercados sobre el Estado, del sector privado contra los servicios públicos y de la creciente desigualdad en todos los órdenes.

Y algo prácticamente admitido por unos y por otros, aunque menos considerado por los conservadores, la mundialización y la globalización coadyuvan al cambio climático y la insostenibilidad ambiental del planeta. Cuestión no menor, y que nos habla de la globalización energética. Los países occidentales están reduciendo y mucho la intensidad energética de sus economías (Acuerdo de París 2016). Los países en desarrollo, por fin, disponen de la energía que les permita abandonar su pobreza secular (la India es el país más renuente a 
aceptar una economía menos carbonizada). No hay desarrollo sin energía abundante, accesible y barata, ni siquiera en un mundo digital. (Bryant, -ed.-, 2015. Hoekstra y Chapagain, 2010. Terceiro, 2009).

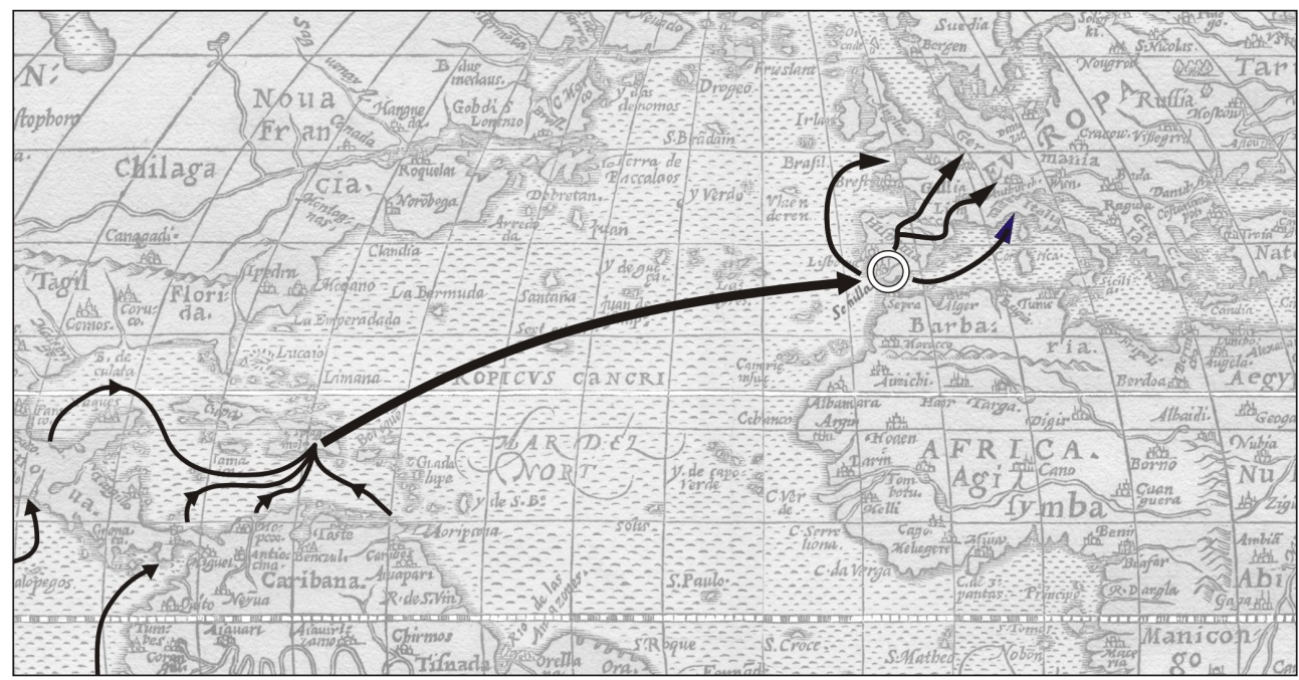

Fuente: elaboración propia.

Sin embargo, la globalización tan denostada por estas posiciones ideológicas progresistas, ha propiciado el vuelco desde los años ochenta del siglo XX y más en el siglo XXI, del pernicioso círculo comercial del subdesarrollo (Toribio, 2003). Hoy, la mitad demográfica del mundo: China, India y los denominados Dragones Asiáticos, nos venden sus mercancías manufacturadas, son nuestros mayores acreedores y sus empresas transnacionales, según datos de Informe UNCTAD (2015), tienen una creciente y ya muy relevante participación en el comercio mundial. Para algunos, puede que exageradamente por ilusión estadística, ya suponen el $40 \%$ de los flujos de inversión extranjera (Guillén y Ontiveros, 2012). Lo último es que todos los países avanzados desean participar del reciente Banco Multilateral de Inversiones, ideado por la China para el Sureste Asiático.

Tras tres décadas de crecimiento históricamente no conocido, en estos Nuevos Países Industrializados de Asia, pese a su autoritarismo político, carencias en la regulación laboral y ecológica y sus extraordinarios desequilibrios y desigualdades sociales y espaciales, estas economías denominadas como emergentes han alcanzado no son sólo la mitad de la población del planeta, sino también el 50\% de la actividad económica mundial (Ruiz, 2008). Lo que era USA en 1950. En los últimos treinta años, han salido de la pobreza millones de chinos, de indios, coreanos, singapureses o taiwaneses, según muestran los indicadores de Desarrollo del Banco Mundial (Chant y McIlwaine, 2008). 
En efecto, Piketty (2013), destaca que el proceso de Mundialización Global está generando un efecto que podemos denominar de doble velocidad. A saber, las diferencias territoriales de la globalización se han atenuado por este "Juego de Tronos" asiático, dado el extraordinario crecimiento del Pacífico económico en convergencia con el declive relativo o finalización de la divergencia histórica del Atlántico norteamericano y europeo (Ferguson, 2011). Lo indiscutible, empero, es el acrecentamiento imparable de la desigualdad en la estructura de la sociedad global (Stiglitz, 2015). Un informe poco sospechoso de reivindicativo e izquierdista por su procedencia (Credit Suisse, 2015), revela con júbilo e interés positivo que el $1 \%$ de la población mundial -mega multimillonarios tanto del Norte desarrollado (sobre todo USA y Reino Unido), como de la Periferia emergente o subdesarrollada (especialmente China y Rusia)-, aquellos que poseen un patrimonio valorado en 667.000 euros o más, tienen tanto dinero líquido o invertido como el $99 \%$ restante de la población mundial. Éstos son unos 36 millones de personas privilegiadas sobre los 7.383 millones de seres humanos que habitan el mundo en febrero de 2016 (Hay y Beaverstock -eds.- 2016).

Esta impresionante brecha en la sociedad globalización -que marca líneas rojas de desigualdad más profundas que las que se dibujaban en la previa a la primera Revolución Industrial británica (Landes, 1999) - entre los mentados privilegiados y el resto de la humanidad, lejos de suturarse, ha seguido ampliándose desde el inicio de la "Gran Recesión” en 2008 y los temores a replicarse en estos inicios del 2016. La estadística de Credit Suisse, una de las más fiables a este respecto, solo deja una lectura posible (Reinhart y Rogoff, 2011). Pese a la aparente convergencia territorial en la mundialización, motivada por el crecimiento asiático, los ricos en la globalización han salido de las crisis globales siendo más ricos, tanto en términos absolutos como relativos.

¿Por qué fracasan los países? Se preguntan Acemoglu y Robinson (2012) y estos autores responden, eso sí, después de un exhaustivo y dilatado estudio de casos en el tiempo histórico y la geografía mundial, que lo que realmente es relevante en la prosperidad de los países es la inclusividad institucional de la economía, de la sociedad y de la política. Mientras que la extractividad de oligarquías y élites dominantes, que asignan recursos y controlan oligopólicamente actividades de alta productividad (animando de forma lacerante a la codicia y la violencia de modo que otros grupos homólogos traten de acceder al control del Estado y de dichos recursos), son las causantes del fracaso de las naciones ${ }^{1}$.

En cualquier caso, volviendo al impacto de la globalización, desde el crecimiento inusitado de las economías asiáticas, mientras que en las otrora economías consideradas como avanzadas, desarrolladas o centrales, donde se halla periféricamente Andalucía, presentan grandes déficits comerciales -menos Japón y Alemania-, la liberalización del comercio, la deslocalización industrial y la fluidez incontrolada de los capitales financieros, han provocado el desmantelamiento de buena parte de la capacidad industrial europea, con millonarias pérdidas de empleos, destrucción de clase media, aumento de la desigualdad y ajuste en el Estado del Bienestar (Fontana, 2011).

1 En un reciente trabajo del Centro de Estudios Andaluces (Arenas, 2016), se demuestran estas hipótesis para Andalucía, desde la Alta Edad Media hasta la primera década del Siglo XXI, la culpa del retraso de Andalucía son sus élites extractivas. 
La paradoja es evidente, las áreas periféricas relativas como Andalucía hemos reclamado históricamente cortocircuitar los círculos viciosos del subdesarrollo basados en el intercambio desigual -concepto estructuralista muy discutido por la evidencia empírica y la teoría institucionalista antes mencionada- y las carencias relativas en dotaciones de infraestructura y capital fijo, entre territorios centrales o periféricos en lo económico y en lo político (Delgado y otros, 2012 y 2014)2. La globalización se ha vuelto, en parte, contra las buenas conciencias europeas y andaluzas que pronosticaron una mayor dependencia del mundo subdesarrollado por mor del librecambismo del que tanto abominaba Carlos Marx (Krugman, 2009. Skidelsky, 2009). Lo que ha ocurrido fehacientemente es que las economías asiáticas, particularmente la China que política e institucionalmente sigue siendo de partido único y comunista, han desarbolado las expectativas y nos están penetrando -también en Andalucía-, condicionando nuestro aparato productivo y societario, destruyéndose colateralmente, logros sociales que costaron un siglo de lucha de clases (Mason, 2016).

La pregunta que nos hacemos es: ¿Cómo juega Andalucía en este panorama global? Éste va a ser nuestro relato en las siguientes páginas, atendiendo en primer lugar, tanto a la posición geoestratégica de los recursos y de la geografía de Andalucía. Sus ventajas comparativas estáticas e históricas, explicadas por la dotación de recursos naturales y culturales. Y, en segundo lugar, a partir de estudios empíricos de la competitividad andaluza, tratar de responder a la pregunta del rol de Andalucía en la globalización luego de la Crisis del 2008. Esperemos que todo no quede retardatario con las malas señales de incertidumbre y volatilidad global y financiera de principios del 2016: restricciones de liquidez, desplome de los emergentes, revisión del crecimiento chino y saturación en los mercados de materias primas. ${ }^{3}$

\section{SOBRE LA POSICIÓN Y SITUACIÓN DE ANDALUCÍA EN EL MUNDO}

Es tópico considerar, por la evidencia empírica y la reiteración de los enunciados, la posición afortunada y estratégica de Andalucía en el globo terráqueo (Cano, -dir.- 1987). Básicamente por tres razones. Una primera, que ubica a Andalucía entre Atlántico y Mediterráneo, como llave entre continentes: África y Europa y el Océano y Mar más transitados hasta el Siglo XXI (ahora el Pacífico, Suárez de Vivero, 2014). Andalucía ofrece una penetrabilidad costera extraordinaria con más de $1000 \mathrm{~km}$. de costa y el Estrecho de Gibraltar. Una segunda, que deviene de esta situación geográfica, y que comporta una constante llegada de pueblos, mestizaje cultural, apertura y colonización, en una situación meridional en Europa (la meridionalidad andaluza), que se torna en un continuado declive luego de la posición central de Andalucía en la Conquista Americana, en una incontestable senda de perifericidad europea desde mediados del Siglo XVII. Y por fin, en tercer lugar, la feracidad natural (climática, edafológica, agrícola y minera), que es muestra de la profunda diversidad anda-

2 Desde 1986, según datos oficiales de la Consejería de Economía de la Junta de Andalucía (2015), Andalucía ha recibido 41.000 millones de euros en Fondos Europeos. La región que en términos brutos más ha recibido de la Unión Europea, fondos que no han propiciado de la manera pretendida la convergencia europea (Jovanovic, 2014). Bien es verdad que ninguna de las regiones consideradas como Objetivo 1 han salido verdaderamente de su estado de postración y proceso divergente (McCann, 2015).

3 Estas son las tendencias que adivina el FMI según las declaraciones de su presidenta en el primer cuatrimestre del 2016. 
luza, de borde meseteño (Sierra Morena), el Valle del Guadalquivir y los 2/3 del territorio andaluz, producto en general, de la orogenia alpina: Las Béticas ${ }^{4}$ (Cuenca Toribio, 2009).

Situación Geoestratégica, Encrucijada histórica de pueblos y Dotación amplia de recursos naturales y culturales. Los tres tópicos de nuestra posición geográfica en el mundo. ¿Sirven todavía, en un mundo global? Desde luego, nuestros estereotipos de situación se han atenuado comparativamente y otras han virado de forma expresiva, creemos a peor.

En efecto, la percepción de las ventajas comparativas históricas tradicionales de Andalucía desde su posición geográfica han evolucionado, por decirlo retóricamente, y las ventajas de "estar en el mapa" (Garfield, 2012) o de "venganza de la geografía" (Kaplan, 2012) nos parece, hace tiempo se han deteriorado (Marchena, 2007). Precisamente por mor de la evolución de la mundialización del siglo XVI. Andalucía no consigue situarse como lugar central sosteniblemente, y se comporta desde este momento como una centralidad aparente por su situación geográfica (particularmente en la Carrera de Indias) y verdaderamente periférica por su rol de tránsito de los metales americanos (Grataloup, 2001). Coadyuvándose una cultura rentista que fue perniciosa, junto a factores de desarticulación con el resto peninsular y el subsiguiente apoyo a Cataluña y el País Vasco por parte del Estado español, en la imposibilidad de una Revolución Industrial a la británica, para Andalucía (Nadal, -dir.- 2003).

La pregunta que nos debemos formular ahora es: ¿Cómo con la globalización se han visto mutadas y perturbadas las condiciones seculares de una posición de Andalucía en el mapa, aparentemente muy positiva, pero realmente nunca suficientemente aprovechada? Ello tiene su encaje en la intrínseca del comportamiento secular andaluz, subdesarrollado y retardatario, cuando las reales ventajas del comercio americano y el fracaso industrial (siglos XVII/ XIX), hacen transitar la virtual centralidad andaluza, hacia un retraso relativo con Europa, que aún no hemos sabido superar (Domínguez, 2003). La globalización en las postrimerías del siglo XX, no ha resuelto nuestra posición en el mundo -o no hemos sabido aprovechar los cambios que propone-, sino que ha profundizado nuestra carga meridional y periférica en la Unión Europea. Mantenemos una posición subsidiaria de Europa, incluso luego del potente desembolso europeo en Andalucía de Fondos Estructurales (Moreno, Renart y Vidal, 2012). Precisamente en la tercera parte de este trabajo ahondaremos en nuestro sitio competitivo en la globalización del siglo XXI.

No hay razones de geografía que nos limiten, algunos piensan que la civilización andalusí aún está buscando el sitio en el mundo, luego de ser conquistada por los castellanos, porque aquí tuvo su máximo esplendor (véase una crítica iracunda a ello en Sánchez-Saus, 2016). Esa geografía determina las dos grandes ventajas comparativas andaluzas, una secular, la agricultura mediterránea y su posterior agro industrialización (la agricultura hidropónica litoral, sobre todo la almeriense y onubense) en el siglo XX (Delgado, 2014). Y otra más reciente, motivada por ese litoral amplísimo antes mentado y la meridionalidad, precios relativos y capacidad instalada, del turismo andaluz ${ }^{5}$ (Wahab y Cooper, -eds.-, 2001).

Sin embargo, por mucho que nuestra retórica al uso nos haga percibir una lejanía de los centros de poder europeos contrapesada, al situarnos en la centralidad logística de la segunda

4 Sobre los hechos geográficos e históricos expuestos más arriba, véase la obra colectiva: Atlas de la Historia del Territorio de Andalucía, Junta de Andalucía, Sevilla 2009, 250 pp.

5 Véase en general, la obra magna dirigida por el Profesor Cano, G., Geografía de Andalucía, VIII Tomos, Ed Tartessos, Sevilla 1987/1988. 
ruta marítima del mundo (Estrecho de Gibraltar) y como espacio de conexión logística y portuaria con África, si bien la realidad sólo permite un aprovechamiento limitado de esta situación geográfica ${ }^{6}$. Más bien, el Estrecho de Gibraltar (Norte/Sur) se comporta como una de las fronteras más duras del mundo en las diferencias de renta per cápita, índices de desarrollo humano e indicadores sociales, educativos y demográficos. El drama de la inmigración ilegal, pateras y refugiados es prácticamente estructural y sin visos de solución real. No en vano, con Tijuana/San Diego (California); Israel/Palestina; Corea del Norte/y del Sur, la frontera de Melilla, es uno de los pocos muros físicos levantados en el Planeta y que responden a las desigualdades Norte y Sur (Schuler, 2010).

Otro sector tradicional andaluz, la minería, también puede ser reflejo de lo que decimos. Se ha hablado del expolio minero andaluz desde épocas remotas, particularmente desde Roma. Sin embargo pasaron mil años, desde la caída del Imperio Romano -mil años- hasta que algunas de las antiguas minas fueron redescubiertas en tiempos de Felipe II, pero sólo la llegada del capital y tecnología, sobre todo británicos, permitió renovar a gran escala, el imponente depósito minero/geológico que es la Faja Pirítica onubense (Checkland, 1967). ¿Colonización o incapacidad endógena de nuestra burguesía regional? Parece que la historia se repite en estos años del Siglo XXI (véase nota a pie de página n ${ }^{\circ} 12$ ).

El fracaso industrial de Andalucía produjo la desarticulación final, si no es por los polos de desarrollo franquistas, entre minería e industria. La globalización ha permitido la reapertura del sector por el tirón de las economías emergentes y la explotación de yacimientos cerrados antes por deseconómicos, por parte de grandes compañías transnacionales europeas, norteamericanas, australianas y sudafricanas. Un sector procíclico y extravertido a las necesidades de los Nuevos Países Industrializados, países que están tratando de salir del subdesarrollo manufacturando materias primas andaluzas, en este caso minerales. Antes era la explotación del desarrollo, ahora es la tracción del subdesarrollo quién ha reciclado y removido el sector minero andaluz. Pero no ha cambiado el sitio estructural de Andalucía en el mundo, ni relativamente hablando con Europa.

Ni la hipótesis de la geografía como determinante de nuestras ventajas comparativas, ni la de la cultura acomodada antes que rica, ni de la ignorancia (Know How) por saber cómo se aprovechan los mencionados recursos de situación andaluces, nos explican ¿Qué le falta a Andalucía? Y cada vez menos la Teoría de la Dependencia. ¿Por qué no se ha comportado Andalucía como una Sociedad Emergente con la ayuda de los Fondos Estructurales Europeos y la globalización? (Cuadrado-Roura -ed.-, 2010). Los indicios tienen desgraciadamente cada vez menos componentes geográficos y da pereza reiterativa abundar en la historia de Andalucía, para achacar todo lo que sucede hoy a lo acontecido siglos atrás, a la manera argentina. Convendrá mirar hacia dentro y desde dentro, sobre todo a las élites andaluzas, también a las élites políticas andaluzas, en vez de desde fuera, para observar cómo se comporta Andalucía en la globalización.

La obsesión de culpar ideológicamente a la globalización de los males de Andalucía, otra vez una interpretación "desde fuera "de nuestros seculares problemas, no se compadece con lo que sucede en otras regiones del planeta, sobre todo los Nuevos Países Industriales Asiáti-

6 Véase el artículo de Rafael Salgueiro aparecido en Diario de Sevilla 9/7/2011, titulado "Las otras cuatro columnas de Hércules". 
cos. La importancia de la geografía y de la fricción económica y tecnológica de la distancia geográfica se han aminorado con la Revolución de las Tecnologías de la Información y la Comunicación, y otros cambios tecnológicos como la contenerización del tráfico marítimo y la competencia espectacular en el precio del sillón aéreo (llamado" low cost").

Habrá que considerar, y algo de ello trataremos en la parte más empírica de este discurso (el capítulo siguiente), si el capital físico, si las transferencias europeas, si la inversión constante en capacidad instalada, es en sí mismo un camino cierto para la convergencia europea, para el desarrollo relativo, para una inserción más afortunada en la globalización. En el caso de Andalucía como comprobaremos, la respuesta es que no. Nos falta inclusividad y competitividad, más tejido empresarial con dimensión y con economías de escala (Martín, 2015).

Andalucía y sus tres décadas de descentralización autonómica han sido espléndidas en el énfasis de la equidad (también territorial) y de la integración social. Por algunos se repite la falta de vertebración (sin explicarse de forma concreta el término) pero el sistema de ciudades andaluz es el más equilibrado del Sur de Europa (incluida toda la Península Ibérica) y las ciudades en la globalización, guste o no guste, compiten (Derudder y otros -eds.-, 2011; Glaeser, 2011). Otra cosa es el localismo pacato, ese que no piensa en lo global para actuar en lo local, o especialmente como ocurre en la escala regional para justificar el retraso sobre otros espacios y territorios de España, de las élites rentistas andaluzas, o con las élites urbanas de las ciudades andaluzas, para culpar de sus fracasos al resto de las ciudades andaluzas, particularmente Sevilla.

Como ya mediremos estadísticamente, la desigualdad de Andalucía, pese a su crecimiento con equidad desde el desarrollo autonómico, con los territorios centrales europeos sigue manteniéndose como demasiada (Cardenete y Ordóñez, 2011) ${ }^{7}$. Andalucía no se mueve en la globalización en el mejor de los mundos posibles, ni cuenta con espacios económicos - se acercan el litoral y el AM. de Sevilla- donde la productividad y la innovación nos encaminen a la convergencia europea, ni a un territorio emergente en la globalización. Bien es verdad -afortunadamente- que tampoco Andalucía a este respecto, presenta ventajas comparativas tipo economías asiáticas: en salario, ausencia o deficiencias en regulación social y medioambiental, precariedad, autoritarismo, extractividad, etc. (López-Rodriguez y Faiña, 2007) ${ }^{8}$. Nos hallamos en esa mediana de dos velocidades, ni competitiva por arriba ni por abajo (Rifkin, 2014). Obvio es que salvando los conocidos archipiélagos económicos (mejor empresariales) de carácter aeronáutico, minero, químico, inmobiliario/turístico, oleícola, hortofrutícola costero o portuario (Jordá y Ruiz, 2009), el territorio andaluz carece de crecimiento autocentrado en la mundialización (Vázquez, 2007). De ahí el valor de las políticas de equidad realizadas hasta ahora, pero con escaso impacto en retroalimentar el crecimiento económico hacia la convergencia europea y la inserción global. Incluso la equidad se difumina con las cifras constantes y estructurales de desempleo desesperante ${ }^{9}$. El empleo lo crean las empresas y no la acción pública por

7 Según Aurioles y Velasco (2006), el histórico subdesarrollo relativo de Andalucía con España y Europa, tiene una explicación relativamente sencilla. En sus dos terceras partes se debe a la insuficiencia del empleo, mientras que la tercera parte restante, a la diferencia de productividad; llegándose a la conclusión de que si se corrigen ambas diferencias, el problema quedaría automáticamente resuelto.

8 Según el Instituto Nacional de Estadística (2015) los costes laborales por trabajador/mes en Andalucía son de 2.276 euros, la media española es de 2502 euros. Costes en los deciles bajos de la pirámide, pero incomparables al vecino Magreb o a los Nuevos Países Industriales asiáticos.

9 Según los informes anuales de la OCDE, el paro de larga duración y el paro juvenil son las dos grandes sombras de la región española con mayor tasa de desempleo $(34,2 \%$ de la población activa, diez puntos superior de la tasa nacional y más de veinte, nada menos, de la europea en 2015). 
sí sola (Vallés, 2003). El mayor error de la descentralización autonómica ha sido pensar que es capaz de animar un desarrollo económico sostenido en un mundo global ${ }^{10}$. Contemplando a las empresas como meros agentes dedicados a traducir incentivos económicos e infraestructuras en inversión, producción y empleo (Márquez, ramajo y Hewings, 2011) ${ }^{11}$.

Decíamos más arriba que las telecomunicaciones y la globalización han hecho que el planeta sea más pequeño y que la geografía física tenga cada vez menor importancia (Polèse y Rubiera, 2009). Nunca antes en la Historia ha sido más fácil crear una empresa desde cualquier parte del mundo y obtener un impacto más global. Andalucía mantiene intactas sus ventajas históricas en posición, situación y recursos naturales y culturales, también como hemos visto, que por mor de la globalización, estas ventajas comparativas estáticas se relativizan, más aún luego de un largo período de tiempo de su no aprovechamiento relativo. Sin embargo, Andalucía mantiene en este mundo hiperconectado el atractivo para vivir aprovechando la mundialización tecnológica. Falta lo que nunca sucedió en Andalucía: engancharse sin retardos a los procesos de cambio tecnológico, que implican mutaciones sociales e institucionales de acomodación a lo que se nos viene: la aceleración de la tecnología, a saber, prácticamente todos los aspectos de la vida serán transformados por la irrupción de la tecnología, que crece de forma exponencial para impactar en todo lo que hacemos y cómo lo hacemos ${ }^{12}$. La eclosión de la Destrucción Creativa. La agenda de inserción pasa por el conocimiento masivo del inglés; de la experiencia internacional; del conocimiento de centros de excelencia formativa en el mundo avanzado; de ambición global; y de resolver problemas planetarios. Las nuevas formas intangibles de las ventajas comparativas dinámicas en la globalización ${ }^{13}$.

En esta suerte de introspección, la idea de buena vida que tienen de sí mismos muchos andaluces (patología ombliguista), y más aún una mirada sobre Andalucía desde fuera (Marchena, 2007), no debieran ser incompatibles con conductas más apegadas a la competitividad, la innovación y el trabajo. Por consiguiente más acordes a la inserción global que demanda actitudes y conductas más racionales y económicas (Castells e Himanen -eds.-, 2014). El reto es cómo hacer compatible el arte de vivir con el arte de producir ${ }^{14}$. El desarrollo económico no es una exclusividad de la Administración, ni es la responsable final de producirlo. Sí lo es de construir una atmósfera favorable a la inversión empresarial en la globalización, con los medios, recursos e instrumentos que competen a lo público. Sin una vocación de prosperidad personal nos tendremos que conformar con vivir en un lugar, Andalucía, excepcional por su renta de situación y sus recursos naturales y culturales, con una renta per cápita media, que estaría entre los cincuenta primeros del mundo, si

10 El porcentaje del Presupuesto de la Junta de Andalucía sobre su PIB es del 21,7\%, sólo superado por la próxima Extremadura $(28,1 \%)$ en el total español, cuya media es del 15,8\% (Ministerio de Hacienda y Administraciones Públicas, 2015).

11 La Densidad Empresarial de Andalucía que es el índice de empresas por mil habitantes es la menor de todas las Comunidades Autónomas españolas (57,2). La media nacional es 66,7 (Instituto Nacional de Estadística, 2015).

12 ¿Cambio de modelo productivo en Andalucía? Nuestra Comunidad Autónoma aparece entre las diez últimas de la UE con un 5,3\% del empleo total ocupado por científicos e ingenieros (EUROSTAT, 2015).

13 Véanse los diagnósticos de las iniciativas, por ejemplo, "Andalucía Open Future" (Universidades Andaluzas y Telefónica, 2014) y de la Research and Innovation Strategy for Smart Specialisation (RIS3) de la Unión Europea para Andalucía, Junta de Andalucía 2014.

14 Tres indicadores elaborados desde los datos del Ministerio de Economía y Competitividad en su informe anual del 2015, nos ponen en aviso de la fragilidad de Andalucía en su inserción global. 
Andalucía fuera un Estado más, entre 175 países. Es el prototipo de una sociedad acomodada antes de haber sido rica; la Historia muestra que ello tiene consecuencias severas ${ }^{15}$.

\section{LA COMPETITIVIDAD DE ANDALUCÍA EN LA GLOBALIZACIÓN DEL SIGLO XXI: UN ANÁLI- SIS EMPÍRICO ${ }^{16}$}

La crisis de 2007 ha supuesto para la estructura y evolución de los sectores estratégicos y del empleo de la economía andaluza, como era de esperar (Cardenete y López, 2012), un mayor y negativo impacto relativo. Particularmente en la divergencia con los restantes territorios españoles y europeos, superior caída del índice de producción industrial, ampliación de la brecha de desempleo, estancamiento estructural y, aún con la mejora del saldo externo, se denota una insuficiente demanda a este respecto (Campoy y Otros, 2014). Sobre la base de la minería de datos y el estudio citado en la nota a pie de página $n^{\circ} 16$, vamos a analizar el sitio de Andalucía en la globalización postcrisis si ello existe (2007/2014), tratando de articular, la relación de costes laborales, competitividad externa y transformación productiva en la economía andaluza.

La reducción de costes laborales nominales (figura 2), con la mejora de la cuota exportadora (figura 3) pero manteniendo el déficit del saldo exterior de la economía andaluza (figura 4) y la mayor caída de los costes laborales reales (figura 5) por la ampliación de la brecha salarial de la economía andaluza (figura 6), que tienen como consecuencia el descenso de la divergencia de productividad aparente (figura 7), pero no de una caída de costes y precios en Andalucía (figura 8), nos conduce a concluir que es completamente necesario alterar la estrategia de competitividad global de la economía andaluza. ¿Por qué?

Porqué la tendencia a la baja de costes laborales se debe a la reducción de la brecha de productividad (efecto composición + mejora efectiva) a costa de la ampliación del gap salarial (por el estancamiento de la compensación real media). Dicho de otra manera, hemos ganado competitividad en el contexto español y europeo, de manera espuria: por la reducción de la población empleada o aumento del desempleo y, lo que es igual de malo, porque los salarios han descendido. Es lo que denominamos aumento de la productividad aparente por mor de menos personas que trabajan para similar nivel de producción y con salarios reales más bajos (figuras 5 y 6). Por consiguiente, la explicación más plausible a este estado de cosas, es que junto a la mayor destrucción de empleos de menor valor añadido (lo que explica las mejoras en la productividad laboral) se haya dado una intensificación de los ritmos productivos (figura 7).

Una competitividad periférica y "asiática", que desde luego no es la más deseable para la inserción global de la economía andaluza, sobre todo cuando hemos visto que no se atisban cambios en el modelo productivo de carácter extractivo y periférico.

15 En la Encuesta de Percepción de la vida cotidiana en Andalucía, Centro de Estudios Andaluces (Noviembre 2015) (universo de 1000 andaluces de más de 16 años), se constata que la nota a la pregunta de "Cómo se vive en Andalucía” es de Notable Alto $(8,18)$, pese a que se suspende en Democracia $(3,96)$, Economía $(3,36)$ y situación política $(3.15)$.

16 Aprovecharemos la minería de datos y su elaboración, gentilmente ofrecidos por el coordinador del Informe sobre la Competitividad de la Economía Andaluza (2015), M.A. Cardenete, director del Departamento de Economía de la Universidad Loyola Andalucía, con la colaboración de la Confederación de Empresarios de Andalucía. Informe parcialmente publicado por la CEA en Sevilla (marzo 2016). 
En efecto, la intensa reducción de los costes laborales en la economía andaluza ha colaborado en la mejora de la cuota exportadora, uno de los principales indicadores para evaluar las ganancias o pérdidas de competitividad externa. De hecho, en comparación con las economías europeas, la caída del indicador de costes en Andalucía sólo se vio superada por la que se produjo en Grecia, como se aprecia en la figura 2.

La mejora y avance del sector exterior también se debe a otros hechos poco alentadores. Es el típico comportamiento primario de incremento de las exportaciones por menores costes y una orientación externa por necesidad, ante la contracción de la demanda de consumo, que comporta una contención de las importaciones productivas (figura 3). Pese a ello se mantiene el déficit externo que ha agotado como vacuna la estrategia de devaluación interna. Vendemos más fuera por menores costes, sobre todo laborales, y compramos menos porque se ha contraído dramáticamente nuestra capacidad de compra. De esta manera, el mantenimiento del déficit externo estructural en Andalucía (figura 4), pese a lo anterior, estaría señalando hacia el agotamiento de la estrategia de devaluación interna emprendida. Ésta, basada en costes laborales, no remedia el desequilibrio histórico entre importaciones y exportaciones en Andalucía, dada su escasa industrialización relativa.

Atendiendo a esto último y relacionándolo a la evolución de los precios en Andalucía (figura 8), nos reforzaría en la idea de que el ajuste salarial (figura 2) ha llegado a su límite como medio de lograr reducciones de precios y mejoras de productividad. Es ineludible a estas alturas actuar sobre otras variables que no sean las compensaciones salariales, que determinan los costes de producción y a partir, de ellos, los de venta de los productos andaluces.

Lo cual tiene dos corolarios: uno, que es necesario poner en marcha políticas que actúen sobre los restantes costes de producción y también sobre los márgenes, factor determinante de los precios finales; y dos, que si se quiere superar el desequilibrio externo que sufre de manera estructural la economía andaluza, haría falta modificar la estrategia de competitividad externa, reorientando nuestras ventas desde ramas de productos de gama baja y menores costes, hacia otros de gama media alta y mayor valor añadido (Cardenete -dir.-, 2016). Lo que se viene llamando, cambio en el modelo y la especialización productiva. En el proceso de globalización, el dinamismo del sector terciario ha sido esencial, Andalucía todavía presenta una escasa orientación exterior de estas producciones, tanto en exportaciones como en inversión exterior ${ }^{17}$.

El crecimiento de las exportaciones andaluzas de mercancías ha sido impulsado (crecimiento incontestable: aumentó un 66,1\%, entre 2008 y 2014 y es la andaluza una economía mucho más abierta que en 2008, trece puntos más) por actividades de fuerte tradición o especial localización en la Comunidad Autónoma, como producción de refino y minerales como cobre o caso de la actividad agroalimentaria, material eléctrico o material de transporte. Y el consabido ciclo de expansión turístico, luego de su notable contracción. Nada nuevo bajo el sol: la principal exportación que realiza Andalucía, proviene del consumo de los no residentes en la región. El consumo turístico (según el Marco Input/Output de Andalucía 2010) suponen el 19,4\% de las exportaciones totales de bienes y servicios de nuestra Comunidad Autónoma. ${ }^{18}$

17 Según datos de la Agencia Andaluza de Promoción Exterior (2015).

18 Véase una descripción resumida de los componentes de nuestra estructura productiva en el artículo de Elena Manzanera del Anuario Joly (2016), con el mismo título (pag. 131). 


\section{Figura 2}

\section{COSTES LABORALES UNITARIOS NOMINALES}

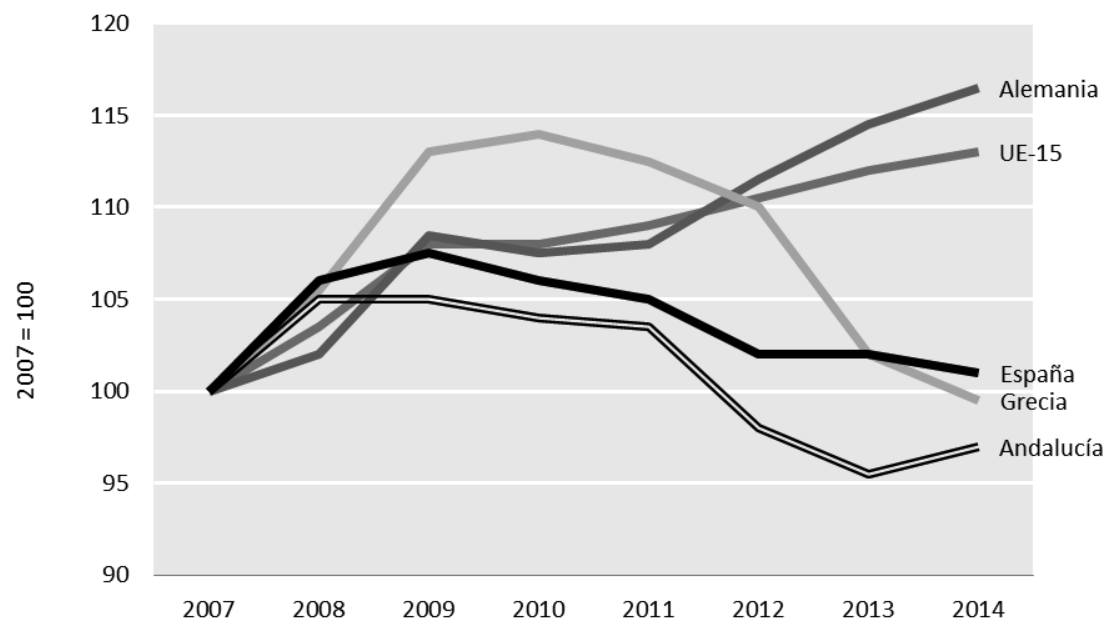

Fuentes: AMECO, IECA, OMC, Cardenete, dir. (2016), y elaboración propia.

Figura 3

COMPETITIVIDAD EXTERNA DE LA ECONOMÍA ANDALUZA

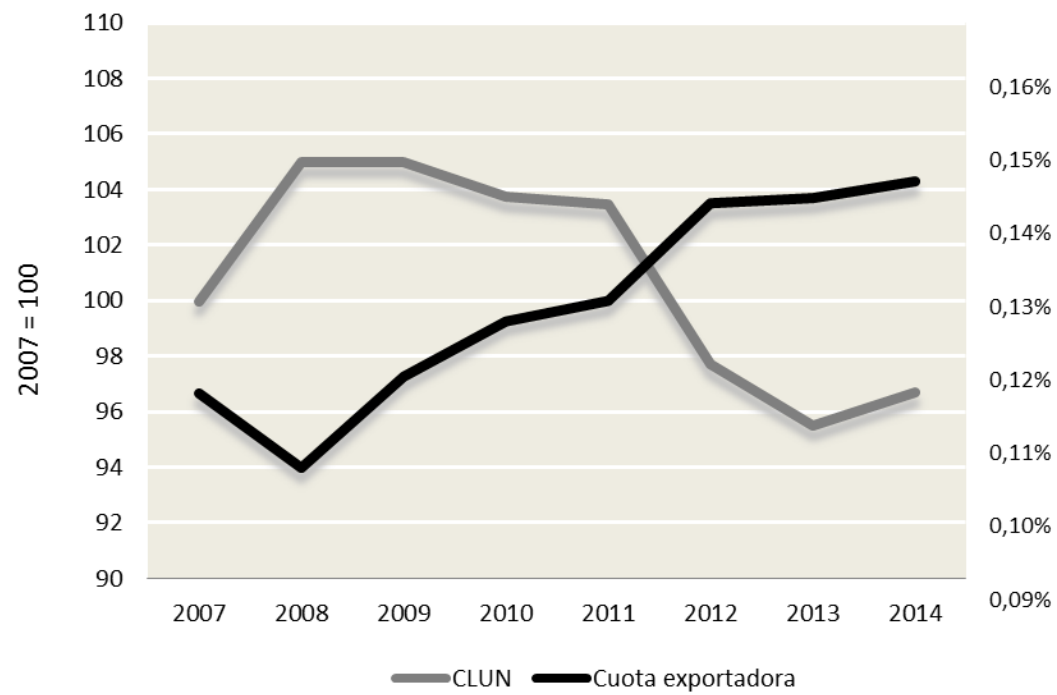

Fuentes: AMECO, IECA, OMC, Cardenete, dir. (2016), y elaboración propia 
Figura 4

SALDO EXTERIOR DE LA ECONOMIAANDALUZA

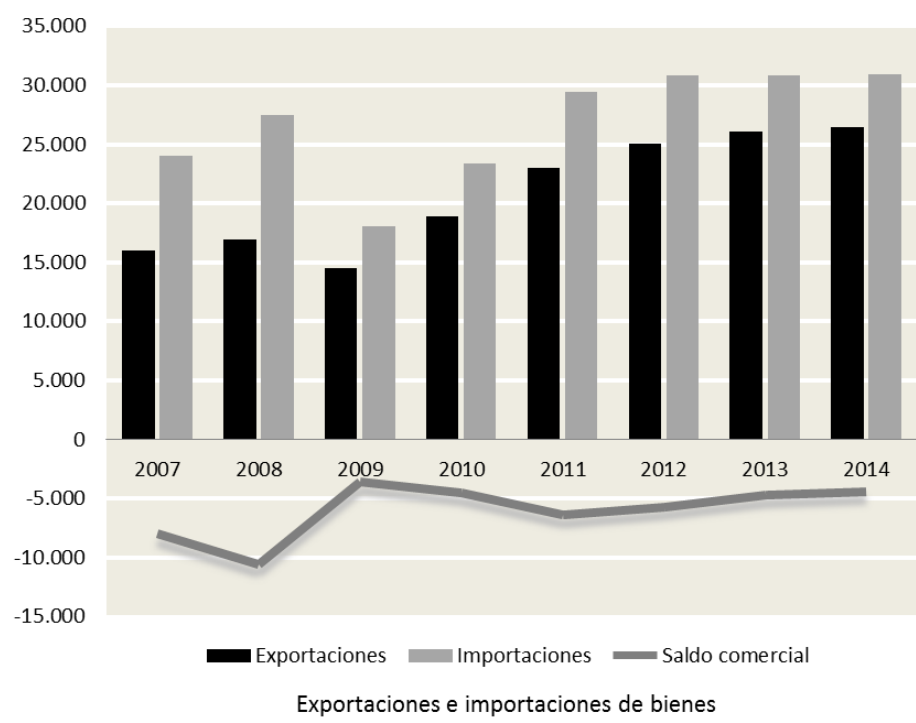

Fuentes: AMECO, IECA, OMC, Cardenete, dir. (2016), y elaboración propia.

Figura 5

COSTES LABORALES UNITARIOS REALES

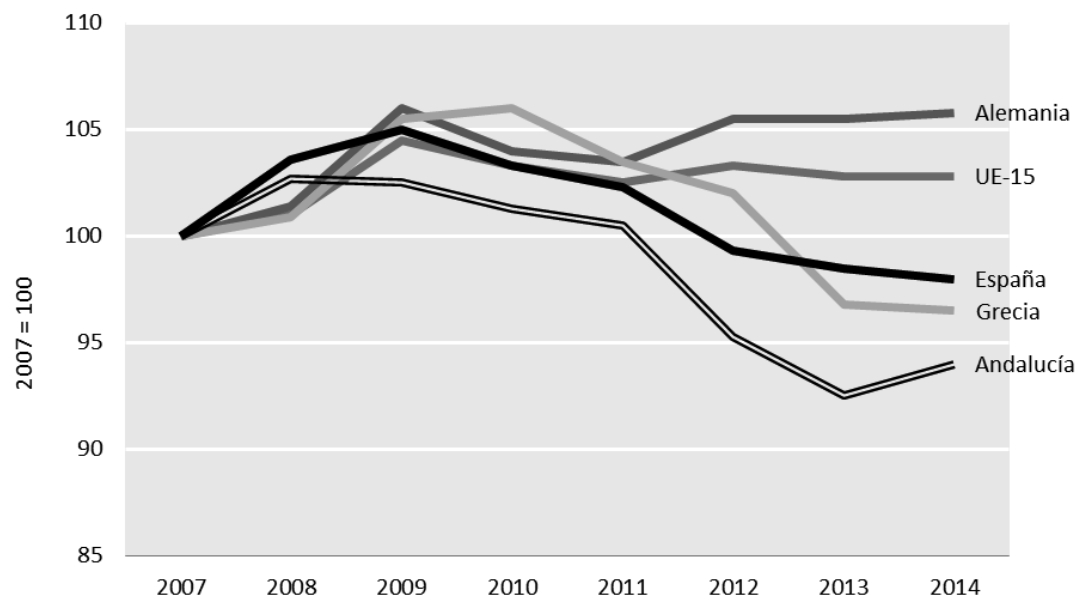

Fuentes: AMECO, IECA, OMC, Cardenete, dir. (2016), y elaboración propia. 


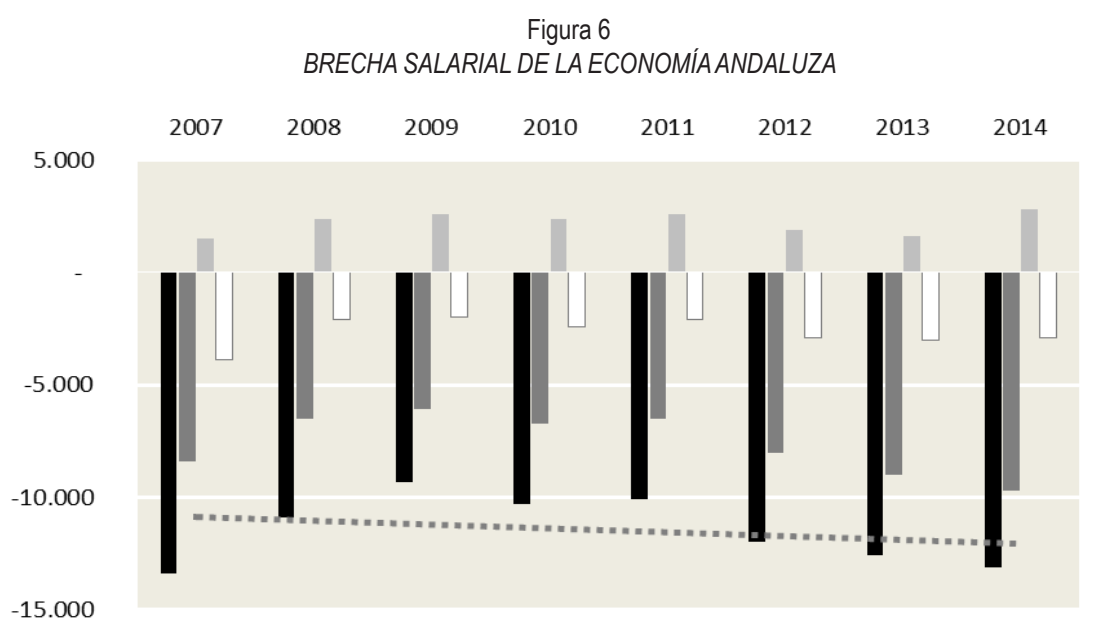

UE-15 Alemania Grecia $\square$ España =... = : Lineal (UE-15)

Diferencia de la compensación real por empleado (salarios y contribuciones empresariales)

Fuentes: AMECO, IECA, OMC, Cardenete, dir. (2016), y elaboración propia.

Figura 7

BRECHA DE PRODUCTIVIDAD DE LA ECONOMÍAANDALUZA

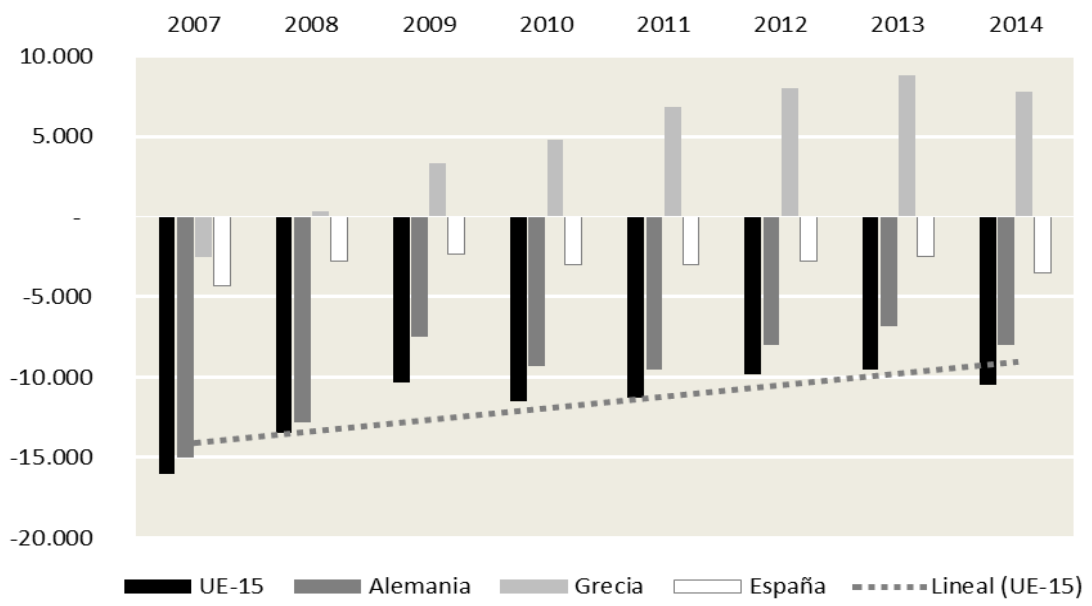

Diferencia de la productividad real media por empleado en Andalucía respecto a otras

Fuentes: AMECO, IECA, OMC, Cardenete, dir. (2016), y elaboración propia. 


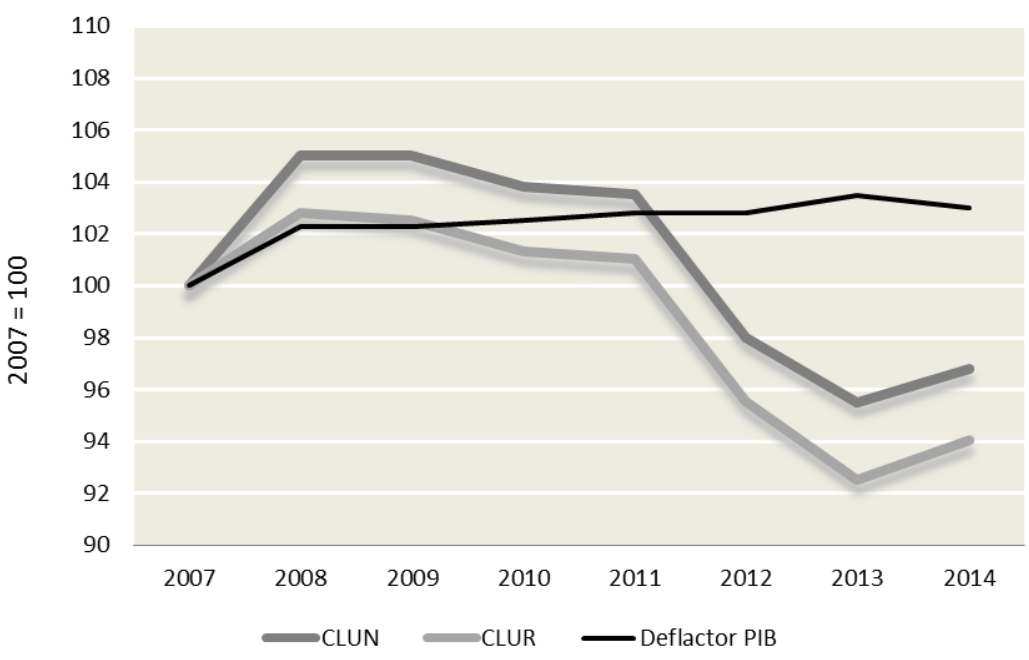

Fuentes: AMECO, IECA, OMC, Cardenete, dir. (2016), y elaboración propia.

Para concluir con el análisis empírico, hemos construido a partir del Informe más arriba citado, una serie de polígonos (figuras 9, 1011 y 12), que comparan Andalucía con el conjunto de Regiones Europeas entre 2008/2012, a través de las series homogéneas del European Cluster Observatory. Se ha estudiado la posición relativa de nuestra Comunidad con el resto del conjunto regional europeo, respecto de una serie de indicadores de "Resultado" (PIB y renta per cápita, desempleo, pobreza, satisfacción con la vida); de "Desempeño Intermedio" (tasa de empleo y desempleo, productividad, patentes y exportaciones); de "Determinantes de Competitividad", en este caso, organizados a su vez en tres dimensiones diferentes: entorno empresarial, especialización productiva y comportamiento empresarial.

Los resultados son realmente adversos para Andalucía, que habría sufrido al final del período estudiado un empeoramiento en la mayoría de los indicadores analizados, al respecto al panorama regional europeo (Regiones UE). En negativo destaca un indicador sobre el resto: el desempleo de larga duración, en la que nuestra región ha caído desde el puesto 150 al 189 de las 192 regiones europeas. En positivo aparece, algo ya comentado prolijamente, la tasa de satisfacción de vida -indicador subjetivo, como veíamos anteriormente- en el que Andalucía ha mejorado posiciones, a pesar del mayor impacto que la crisis ha tenido en la economía andaluza, respecto a la europea y la española en su conjunto (figura 9).

También es destacable nuestro esfuerzo en patentes en los últimos años, que tienen que ver con las inversiones en I+D de última generación en nuestra región. Es una luz en el túnel de la insuficiente densidad tecnológica de Andalucía; muy relacionada, por cierto, con la reorientación de Fondos Europeos desde el capital físico al intelectual productivo. Mejora- 
mos en productividad aparente como ya habíamos adelantado antes, en comparación con las Regiones UE; y somos desgraciados campeones en los indicadores de desempleo general y juvenil y en las tasas de empleo general y femenino (figura 10).

En los indicadores de entorno empresarial (figura 11), destaca el rezago andaluz en formación profesional que contrasta con el alto porcentaje de estudiantes universitarios y de formación continua. Realmente, una relación poco afortunada para el momento económico. Se destaca el esfuerzo realizado en I+D público, pero dicho esfuerzo no se ve reflejado en el nivel general de recursos humanos en el ámbito de la ciencia y la tecnología, ni tampoco en el porcentaje del total de trabajadores dedicados a este tipo de actividades.

La especialización productiva y el comportamiento empresarial reflejado en la figura 12 , tienen mucho que ver con lo anterior. Donde nuevamente se destaca que nuestra posición es más baja que en la de entorno empresarial (figura 11) en comparación con las Regiones UE. Esta constatación apunta en una doble dirección, la débil especialización productiva y comercial de Andalucía y que el empeño en I+D de carácter privado ha sido menor que el público. Ambos aspectos se encuentran negativamente articulados con una estructura productiva de magro valor añadido, y con escaso incentivo para emprender actividades de investigación aplicada. Nuevamente destacan el incremento de patentes en este sombrío panorama.

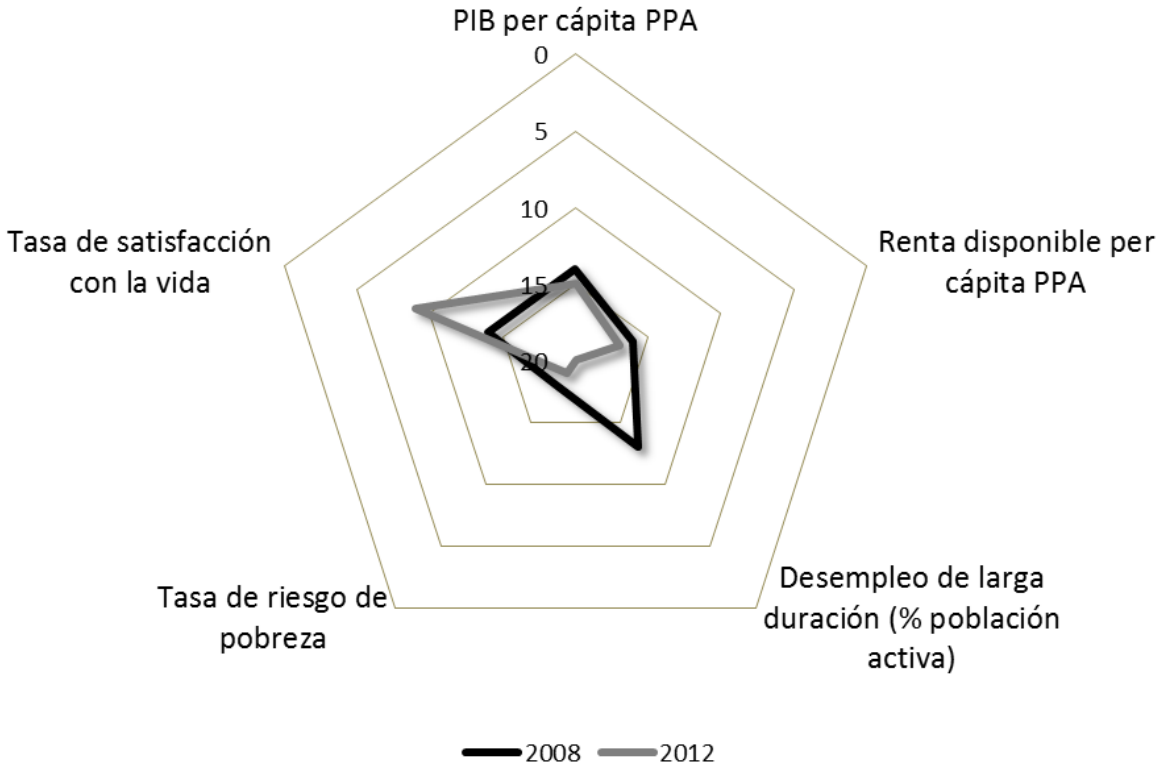

Fuentes: European Cluster Observatory, Cardenete, dir. (2016) y elaboración propia. 


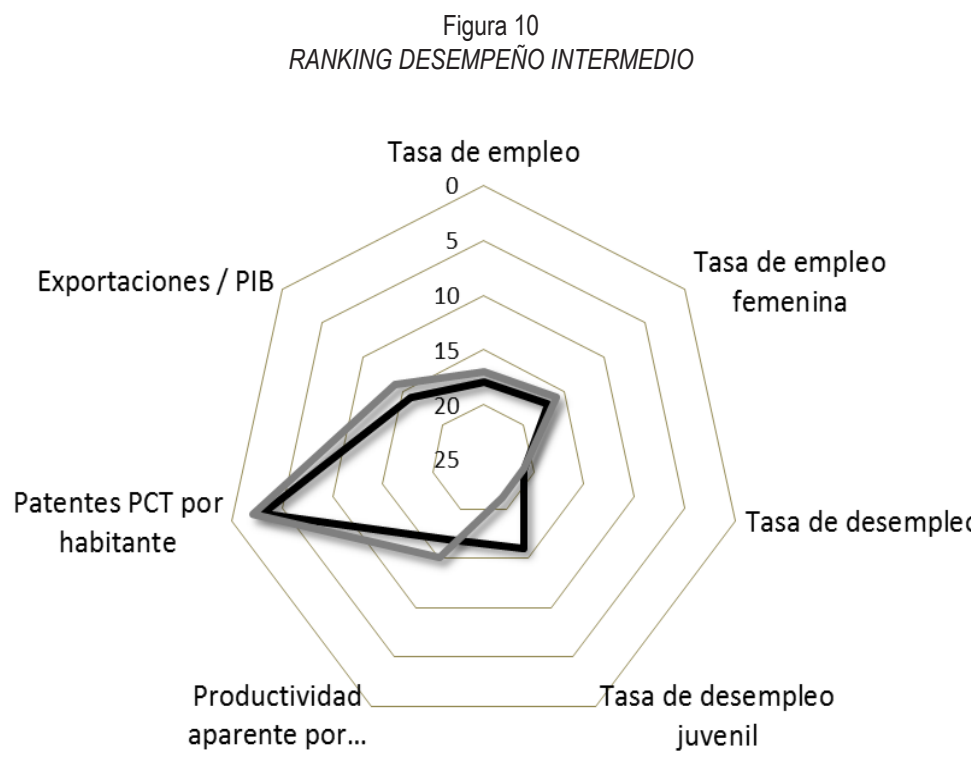

$\longrightarrow 2008 \longrightarrow 2012$

Fuentes: European Cluster Observatory, Cardenete, dir. (2016) y elaboración propia.

Figura 11

RANKING ENTORNO EMPRESARIAL

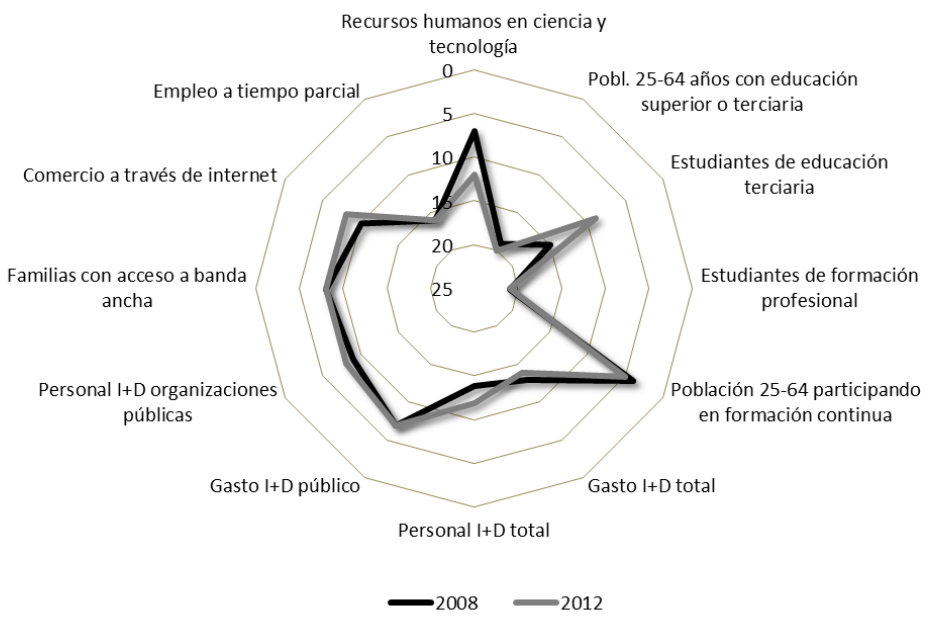

Fuentes: European Cluster Observatory, Cardenete, dir. (2016) y elaboración propia. 


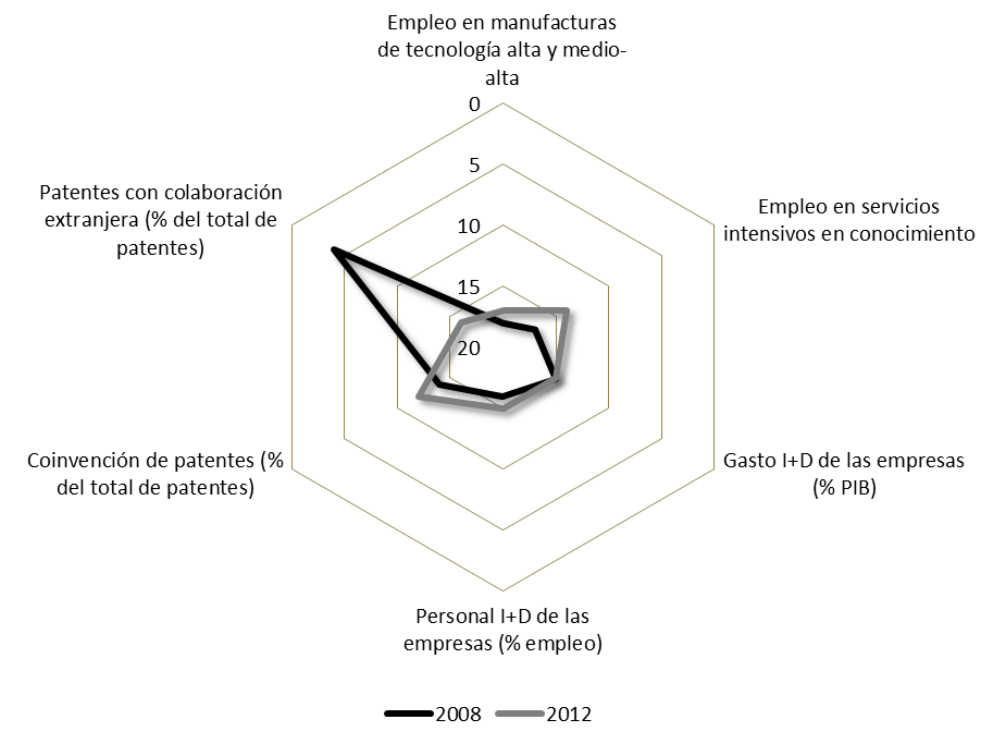

Fuentes: European Cluster Observatory, Cardenete, dir. (2016) y elaboración propia.

En síntesis, son las patentes y su buena posición relativa, el hecho alentador de este análisis empírico, que se oscurece dramáticamente ante la grave situación del mercado de trabajo, que necesita de mejoras urgentes en la educación profesional. La crisis ha propiciado un mayor rezago y empeoramiento relativo, pese al esfuerzo público en $\mathrm{I}+\mathrm{D}$ y un repunte del privado. Pero prima la débil especialización productiva andaluza y su escasa mejoría en estos últimos años. Ésta tiene que ver con un repunte de la demanda interna y la confluencia de factores (mejora relativa de la confianza) que ha permitido que el consumo privado crezca en 2015 (3,8\% en tasa anual), el triple que en 2014 y el de la inversión (6,7\%) cuatro veces superior a 2014. Lo peor, la economía andaluza, según cálculos de la Comisión Europea, está condenada a un nivel de desempleo superior al 20\%, en ausencia de reformas estructurales; una de las primeras que debiera acometerse: nuestro papel en la inserción internacional.

\section{A MODO DE CONCLUSIONES: CAMBIOS URGENTES PARA LA GLOBALIZACIÓN ANDA- LUZA}

Sobre la globalización en Andalucía, podría tomarse una actitud ofensiva o defensiva. A saber, cabe la tópica dialéctica de, por un lado: ¿Es ineludible acatar el fenómeno? ¿Cómo nos cerramos? ¿Es bueno cerrarse? ¿Es posible evitar la globalización? ¿Merece la pena perder el tiempo en tal diatriba? O, por consiguiente ¿habrá que buscar la mejor inserción en el mundo global? Por otro y por el contrario, la globalización nos ha asignado un papel depen- 
diente en la división internacional del trabajo, al que debemos resistir y renunciar. En principio un problema nominal: Andalucía ni se globaliza ni deja de globalizarse, son las empresas que actúan en Andalucía las que se internacionalizan o no. El sector público hará políticas o no que coadyuven a ello o lo contrario. El entorno empresarial será el que estratégicamente apueste o no por la globalización. En ese sentido no hay duda: la declamación de las políticas públicas andaluzas es la de externalizar la producción de las empresas que operan en nuestro suelo, sean o no sean de capital regional.

El problema subyacente es considerar de quién es la responsabilidad de perder otra vez otra oportunidad histórica, o de ensimismarnos sobre la culpabilidad externa y conspirativa de nuestra situación. Por descontado, manifiestamente mejorable, si atendemos a nuestras ventajas comparativas y oportunidades clásicas, de nuestra posición geográfica, la dotación de recursos naturales y geográficos y, ahora, el enorme desarrollo de la educación superior y un relativamente alto porcentaje de gasto público en I+D y su materialización en patentes. Por ende, las reales potencialidades del sector minero, agroalimentario y turístico - para algunos sólo economía extractiva - y la mirada sectorial estratégica en agua, electricidad y metalurgia.

Lo real es que la Crisis de 2007 ha tenido un mayor impacto en la economía andaluza que en el resto de las economías española y europea y al mismo tiempo, como es costumbre histórica, la recuperación está siendo más lenta. Andalucía, pese a los incontestables progresos en Equidad y Estado del Bienestar, se encuentra en una situación de estancamiento de su estructura productiva: atendiendo a los datos oficiales, en el período, 2008-2015, la economía andaluza ha reducido casi en un $10 \%$ su tamaño, particularmente el sector de la construcción que se ha achicado a la mitad. La economía andaluza se ha vuelto más abierta (tasa de apertura próxima al 100\%, más de 13 puntos por encima a la del 2008). El volumen de las exportaciones de bienes y servicios suponen el 44,4\% del PIB; el desequilibrio externo sigue siendo del $7.6 \%$ y las importaciones han crecido en tres puntos. La inversión productiva ha caído abruptamente del $28 \%$ al $16,9 \%$, y lo peor es que en dicho periodo se han reducido en Andalucía un $21 \%$ las horas de trabajo asalariado. Pero, coinciden casi al detalle, las ramas productivas que poseen mayor Valor Añadido Bruto entre 2008/2015. Es decir, la crisis no ha reorientado, sólo adelgazado y en algunos sectores de manera aguda, su peso relativo y real. De 56 ramas, las que más peso relativo contienen son administración pública, alojamiento y restauración y, pese a su descenso estrepitoso, la construcción. ${ }^{19}$ Por el contrario, las ramas que muestran un bajo índice de especialización y que además han reducido su peso en el período considerado son los sectores manufactureros e industriales, tipo productos farmacéuticos, productos informáticos, maquinaria y equipos e industria textil, transporte marítimo y aéreo servicios de consultoría informática

En síntesis, la crisis, lejos de haberse convertido en una oportunidad aprovechada por la economía andaluza para alterar su estructura productiva -clave para cualquier potencial mejora de su competitividad externa- ha reafirmado sus debilidades: una tasa de desempleo de larga duración, general, juvenil y femenina inaguantable con consecuencias de exclusión social $^{20}$; formación y pérdida de capital humano; escaso tamaño de las empresas andaluzas y

19 Sobre las afirmaciones de los párrafos anteriores a la nota, véase el artículo de Elena Manzanera, "La estructura productiva de Andalucía”, en el Anuario Joly Andalucía, Sevilla 2016.

20 Los datos que arroja La Encuesta de Condiciones de Vida del INE (2016) y recogidos por el Defensor del Pueblo de Andalucía, en Sesión Parlamentaria de 24 de Mayo de 2016, son deprimentes para nuestra Región. 
de sus apuestas por el I+D+I; falta del reconocimiento social del empresario (más aún: falta de ellos mismos) y de la investigación; y ausencia de reconocimiento externo de los productos andaluces (véanse mapas de las figuras 13 y 14).

Figura 13

SISTEMAS PRODUCTIVOS INDUSTRIALES Y AGROPECUARIOS MADUROS EN ANDALUCÍA

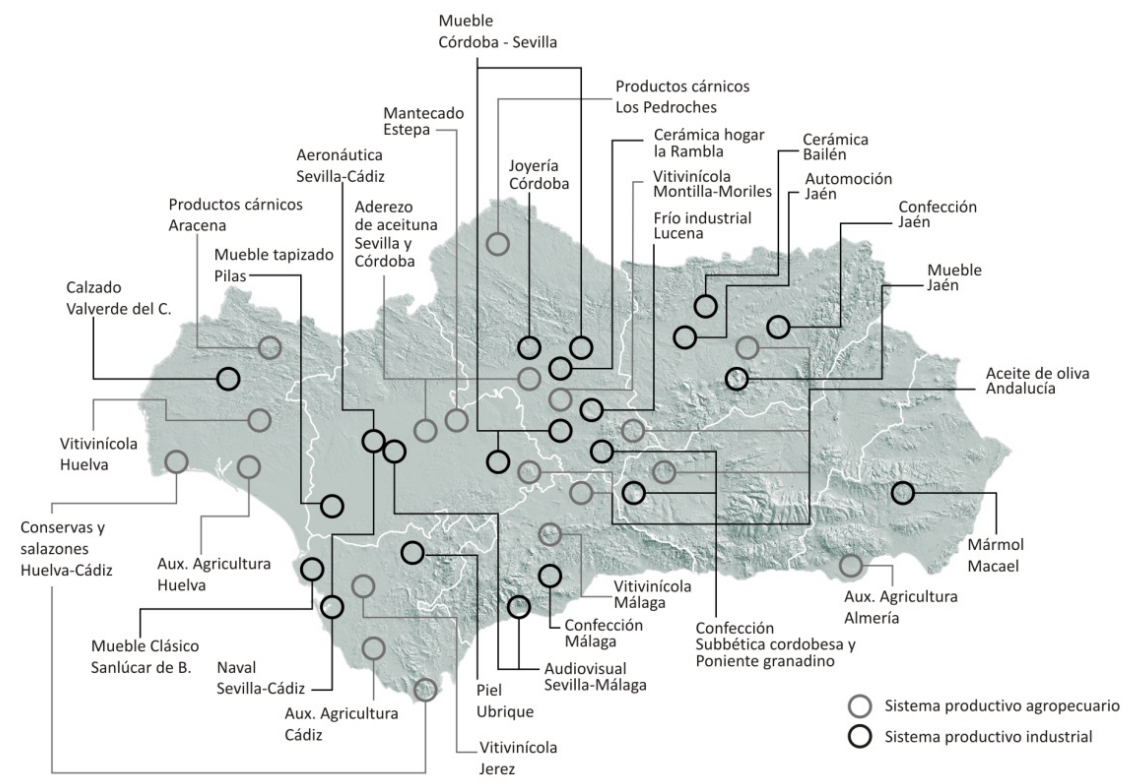

Fuente: elaboración propia.

Figura 14

DISTRIBUCIÓN TERRITORIAL DE LA OFERTA DE ALOJAMIENTO TURÍSTICO EN ANDALUCÍA

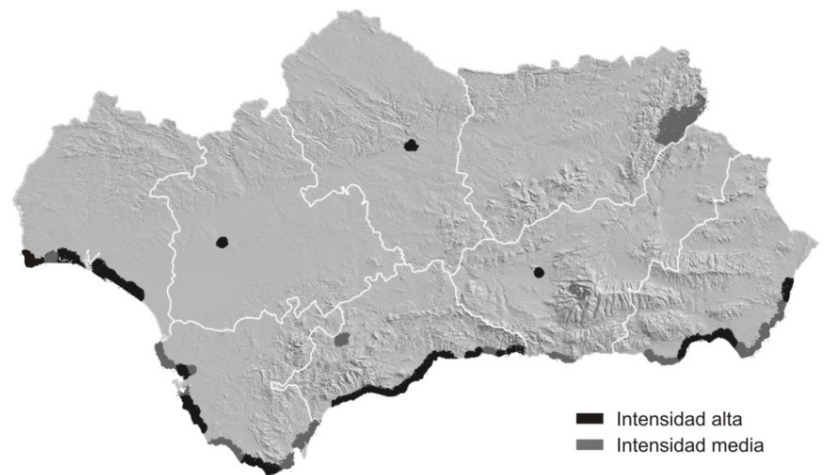

Fuente: Registro de Turismo de Andalucía (RAT), y elaboración propia. 
Las claves son bien conocidas: la debilidad de la industria manufacturera y la carencia de industria tecnológica propia. Andalucía ha realizado un ajuste de los costes laborales extremo, que ha sido marcadamente más intenso que en prácticamente todas las regiones europeas, pero siente a pocos kilómetros físicos y en la mundialización, la competencia de regiones emergentes con menores costes: la doble velocidad de la competitividad andaluza que ha agotado su proceso de devaluación interna basado casi exclusivamente en costes laborales. Como hemos visto, ello se comprueba en la posición notablemente rezagada en Andalucía con respecto a las Regiones UE en los indicadores de desempeño intermedio (tasas de empleo, productividad y exportaciones) y resultados (PIB y renta per cápita, desempleo y somos líderes, como de costumbre, en la satisfacción con la vida).

Dentro de las dimensiones determinantes de la competitividad, Andalucía presenta posiciones muy mejoradas en los indicadores de entorno empresarial. Sin duda la labor inversora de la Administración Pública en capital físico, formación, infraestructura e I+D, y particularmente la dependencia andaluza a los Fondos Europeos, tienen buena explicación de ello. Pero sigue siendo, muy débil el tamaño, la competitividad y la internacionalización del empresario andaluz y es extraordinariamente magra, la especialización sectorial de la economía andaluza, muy debilitada tecnológicamente, extractiva y de un valor añadido, por su escaso componente manufacturero y tecnológico, también manifiestamente mejorable.

La culpabilidad es de ellos, de la economía global: ¿De la globalización? ¿De una División Internacional del Trabajo inmisericorde que nos aloja desde la Carrera de Indias en una posición periférica relativa y bruta? ¿Nos han asignado desde las regiones centrales este rol periférico, extractivo y dependiente? ¿Somos responsables de las oportunidades pérdidas los andaluces en su generalidad, o las élites andaluzas? ¿Nuestras ventajas comparativas estáticas y dinámicas las hemos sabido aprovechar convenientemente? ¿Estamos en la senda de las regiones emergentes? ¿Somos responsables de la perifericidad andaluza, los propios andaluces?

Una respuesta cómoda sería la salomónica: una mezcla de parte y parte con porcentajes de geometría variable. El razonamiento recurrente es que la culpa es de los de afuera, el discurso paralizante es él que tiene que ver con la incapacidad secular andaluza. Diríamos más bien de las élites económicas, culturales y profesionales andaluzas. Lo que es incontrovertible es que Andalucía es otro espacio geográfico desde el advenimiento democrático y la descentralización autonómica: en infraestructura física, dotaciones para la mejora del entorno empresarial, formación en general y calidad del sistema sanitario. No podemos achacar nuestra débil inserción mundial al entorno productivo, más bien a la insuficiencia de la competitividad empresarial y a la omnipresencia de la Administración Regional.

En 2016, atendiendo a indicadores convencionales, la mayoría de los países de la zona euro han salido de la crisis y se enfrentan a nuevos desafíos en la globalización. Ni España ni Andalucía han recuperado sus niveles de PIB del 2009 y han vuelto a unas tasas de paro, que podríamos considerar de "pleno desempleo". La impresión actual es que no hemos aprendido de la crisis: se mantienen parámetros de cultura especulativa (inversión financiera e inmobiliaria) sobre los de cultura empresarial (inversión productiva). Toda una cultura económica de ganancia rápida, "burbujas" y limitado esfuerzo, que desgraciadamente impregna buena parte de los decisores económicos en Andalucía. Quizás el comportamiento de estas actitudes rentistas sea lo más negativo, en las oportunidades que pudieran encontrarse en esta 
globalización postcrisis. Aquellas elites que están en la tesitura extractiva de que la coyuntura mejore y poder acogerse nuevamente a las subvenciones y a ciertos privilegios de la contratación pública, es decir los buscadores de renta, y no los emprendedores productivos.

Nos decantamos por un cambio del modelo productivo (un tópico) que tiene que ver en Andalucía, con un cambio de las condiciones institucionales, de mayor inclusividad, competitividad empresarial no basada en los costes salariales exclusivamente, y densidad tecnológica. Y en un cada vez mayor consenso de sin despreciar el papel competente y estratégico del turismo, convertir en prioridad material desde el ámbito de las políticas públicas y las decisiones empresariales, la industrialización de Andalucía. El "gap" por excelencia de la falta de especialización de nuestro modelo productivo en la globalización.

No se han aprovechado eficientemente, o es lo que muestra la evidencia empírica postcrisis, las Ayudas Europeas que han regado Andalucía durante dos décadas a un promedio anual de 2500 millones de euros, que han contribuido fehacientemente a nuestro capital físico y de articulación territorial, pero no a la reorientación de una mayor especialización industrial y de emprendimiento privado realmente productivo y no meramente especulativo y rentista. La Administración Autonómica es de por sí más cuantiosa que algún PIB de país europeo. Se acabó la época de marcar horizontes cuantitativos de empleo, por la de diseñar e iniciar un camino rotundo de orientación estratégica de los ámbitos, particularmente industriales, de oportunidad y negocio en la globalización y externalización de Andalucía. Ello parece ineludible, defenderse traerá más dolores de cabeza, lo posible es insertarse ofensiva y positivamente. El cambio mental y de apoyo púbico al emprendimiento productivo, nos resulta esencial en este proceso de inserción ofensiva. Menos consignas y más medidas al respecto de la Junta de Andalucía, son indispensables.

Diría un anglosajón ¿Cómo se hace esto, cuál es su "Know How”? Sin duda, mirarnos a nosotros mismos, a nuestras responsabilidades y particularmente a la de las élites regionales -una visión institucionalista-, para que soporten mayores cuotas de responsabilidad y participación empresarial y menos de superestructura empresarial rentista. A una configuración operativa de la Junta de Andalucía pegada al crecimiento económico -ha sido muy eficiente en su faceta equitativa- y a la inserción competitiva en la globalización de Siglo XXI. Véanse los mapas de las figuras 15, 16, 17 y 18.

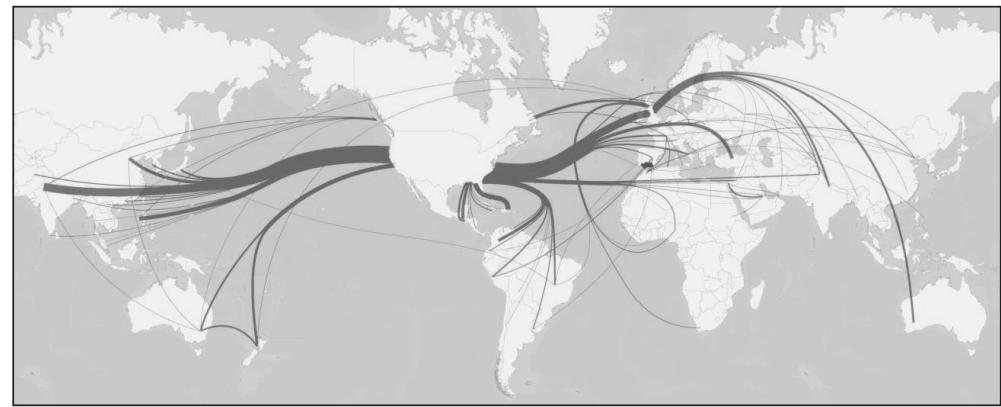

Fuente: TeleGeography (2010), y elaboración propia. 
Figura 16

ANDALUCIAA EN RELACIÓN CON LOS FLUJOS COMERCIALES MUNDIALES.

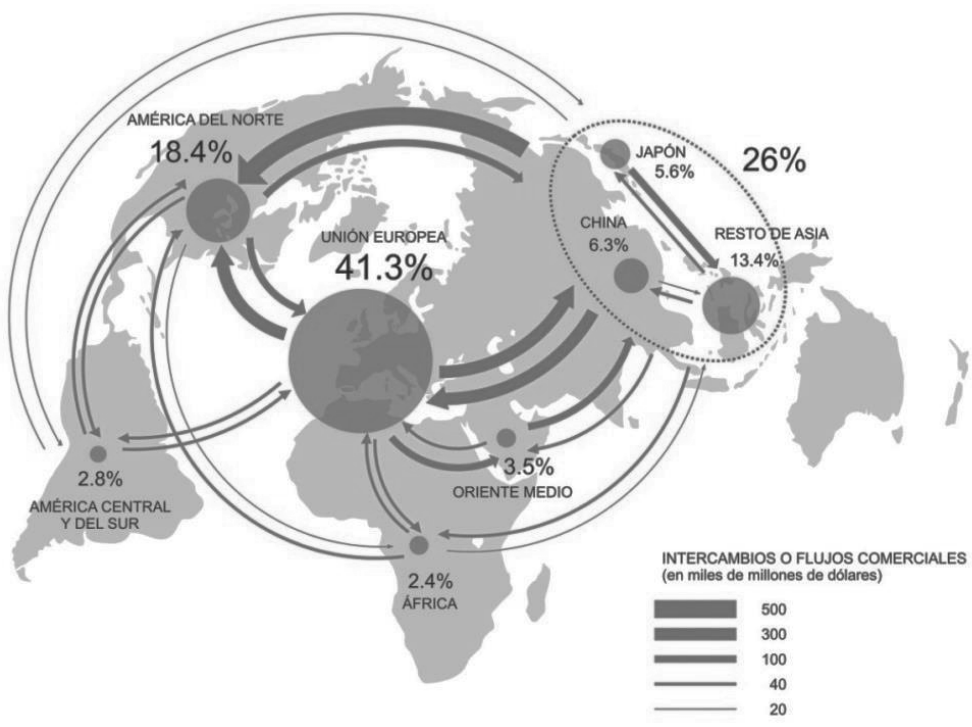

Fuente: Atlas Le Monde Diplomatique (2006), y elaboración propia.

Figura 17

ANDALUCÍA EN RELACIÓN CON LAS ÁREAS DE LIBRE COMERCIO

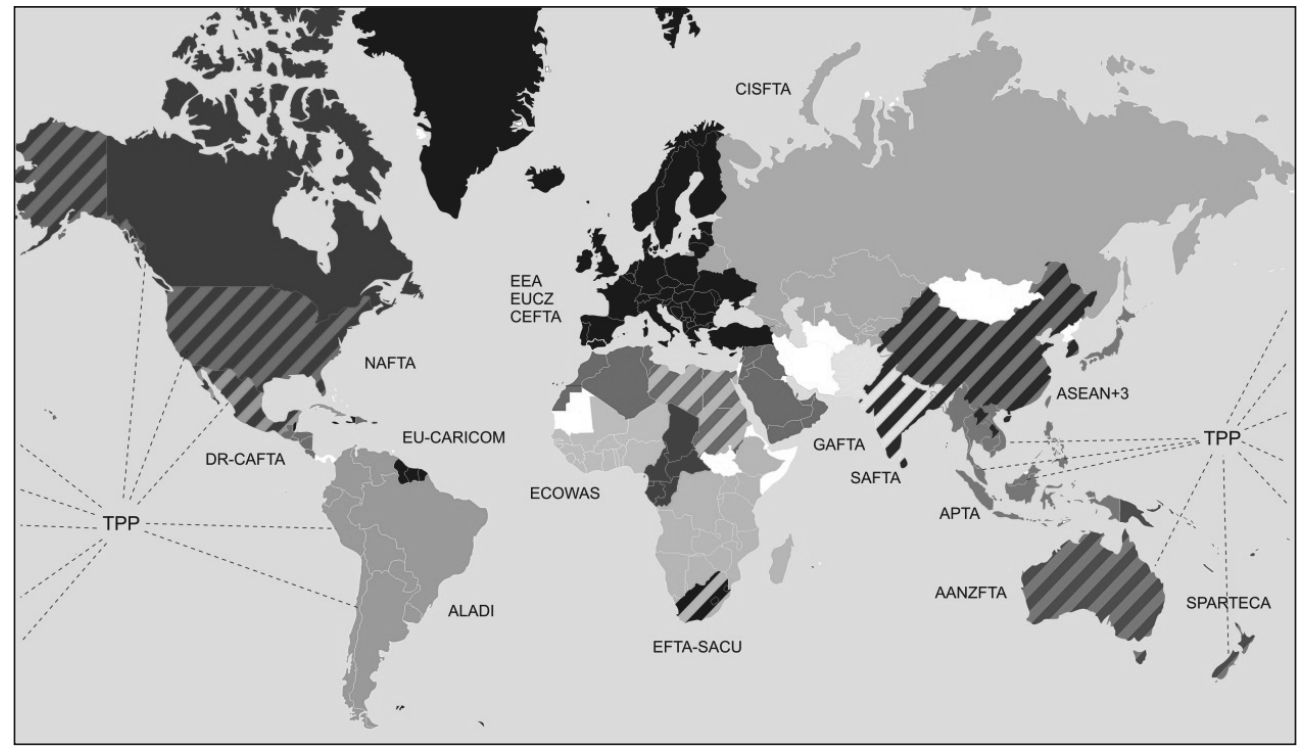

Fuente: Viktor Kryvenko (2016), y elaboración propia. 


\section{BIBLIOGRAFÍA CITADA}

ALBURQUERQUE, F. (2008): “Innovación, transferencia de conocimiento y desarrollo económico territorial e Andalucía. Una política pendiente". Arbor: ciencia, pensamiento y cultura, Madrid 2008, no 732, pp. 687-700.

ARENAS, C. (2016): Poder, economía y sociedad en el sur. Historia e instituciones en el capitalismo andaluz. Centro de Estudios Andaluces, Sevilla, $651 \mathrm{pp}$.

AZCARATE, B. y MONTESA, F. (Eds.) (2011): El Atlas de las Mundializaciones. Le Monde Diplomatique y UNED, Madrid,186 pp.

AURIOLES, J. y VELASCO, R. (2006): Cartas sin dirección: pensando en economía desde Andalucía. Unicaja, Cádiz, 154 pp.

BOORSTIN, D. (2000): Los Descubridores. Editorial Crítica, Barcelona, 628 pp.

BRYANT, R.L. (Ed.) (2015): The International handbook of political Ecology. Elgar, Londres, $720 \mathrm{pp}$.

CAMPOY, M.P. y OTROS (2014): “Analysis of Structural Changes in Andalusian Economy Using Accounting Matrices", WP Series WIFO, 486/2014.

CANO, G. (Dir.) (1987): Geografía de Andalucía Tomo I. Ed. Tartessos, Sevilla, 320 pp.

CARDENETE, M.A. (Dir.) (2016): La Competitividad de la Economía Andaluza. CEA, Sevilla, $62 \mathrm{pp}$.

CARDENETE, M.A. y ORDÓÑEZ, M. (2011): “Metodología de la Matriz Casual para el análisis del cambio estructural: una aplicación para la economía andaluza". Investigaciones Regionales, Madrid, $\mathrm{n}^{\circ}$ 20, pp. 153-164.

CARDENETE, M.A. y LÓPEZ, M. (2012): "Estructura y evolución de los sectores económicos estratégicos y del empleo de la economía andaluza a partir del marco Input-Ouput 1995-2000-2005". Revista de Estudios Regionales, no 95, pp. 39-72.

CASTELLS, M.E y HIMANEN, P. (Eds.) (2014): Reconceptualizing Developement in The Global Information Age., Oxford University Press, Oxford, $460 \mathrm{pp}$.

CHANT, S. y McILWAINE,C. (2008): Geographies of Development in the 21st. Century, Elgar, Londres, $384 \mathrm{pp}$.

CHECKLAND, S. (1967): The Mines of Tharsis. University of Glasgow, Glasgow 1967, 166 pp. CREDIT SUISSE (2015): Global Wealth Report 2015.Zurich, 64 pp.

CUADRADO-ROURA, J.R. (Ed.) (2009): Regional Policy, Economic Growth and Convergence. Lessons from The Spanish Case. Springer-Verlag, Amsterdam, $311 \mathrm{pp}$.

CUENCA TORIBIO, J.M. (2009): Teorías de Andalucía, Ed. Almuzara, Córdoba, 145 pp.

DELGADO, M. y OTROS (2012): "La economía andaluza durante las tres últimas décadas. 1981-2011”, en Andalucía. Identidades culturales y dinámicas sociales, Centro de Estudios Andaluces, Sevilla, pp. 97-132.

DELGADO, M. y OTROS (2014): “Andalucía en la división territorial del trabajo dentro de la economía española. Una aproximación a la luz de su metabolismo socioeconómico. 19962010". Revista de Estudios Regionales, n 100, pp. 197-222.

DELGADO, M. (2014): "La globalización de la agricultura andaluza. Evolución y vigencia de la cuestión agraria en Andalucía", en La cuestión agraria en la historia de Andalucía, GÓNZALEZ DE MOLINA, M. (Coord.), Centro de Estudios Andaluces, Sevilla, pp. 99-132. 
DERUDDER, B., HOYLER, M., TAYLOR y WITLOX, F. (Eds.) (2015): International Handbook of Globalization and World Cities, Elgar, Londres, 584 pp.

DOMÍNGUEZ, A. (2003): Andalucía ayer y hoy. Ed .Sarriá, Málaga, 202 pp.

FERGUSON, T. (2011): “Las seis aplicaciones “asesinas” para prosperar”, Conferencia en Internet: www.ted.com/talks/niall ferguson the 6 killer apps o prosperity?, Julio 2011.

FONTANA, J. (2011): Por el bien del Imperio. Historia del mundo desde 1945. Círculo de Lectores, Barcelona, $1242 \mathrm{pp}$.

FRIEDMAN, TH. (2005): La tierra es plana. Breve Historia del mundo globalizado del siglo XXI. MR ediciones, Madrid, $495 \mathrm{pp}$.

GARFIELD, S. (2012): En el mapa. De cómo el mundo adquirió su aspecto. Taurus, Madrid $478 \mathrm{pp}$.

GLAESER, E. (2011): El Triunfo de las ciudades. Taurus, Madrid, 494 pp.

GRATALOUP, CH. (2010): Géohistoire de la Mondialisation: le temps long du monde. Armand Collin, París, 381 pp.

GRUZINSKI, S. (2010): Las cuatro partes del mundo. Historia de una Mundialización. Fondo de Cultura Económica, México, 480 pp.

GUILLÉN, M. y ONTIVEROS, E (2012): Una nueva época. Los grandes retos del siglo XXI. Galaxia Gutemberg, Madrid, $191 \mathrm{pp}$.

HAY, I. y BEAVERSTOCK, J. (Eds.) (2016): Handbook on Wealth and the Super-rich. Elgar, Londres, $560 \mathrm{pp}$.

HARVEY, D. (2012): El enigma del capital y las crisis del capitalismo. Akal, Madrid, 239 pp.

JORDÁ, R. y RUIZ , F. (2009): “Comportamiento innovador de las empresas internacionalizadas por ámbitos territoriales en Andalucía. Flujos y Sistemas”. Boletín de la Asociación de Geógrafos Españoles, n⿳0 50, pp. 315-348.

JOVANOVIC, M.N. (2014): The economics of European Integration, Second Edition. Elgar, Londres, $1056 \mathrm{pp}$.

KAPLAN, R. (2012): La venganza de la Geografía. RBA libros, Barcelona, 478 pp.

KRUGMAN, P. (2009): El retorno de la economía de la Depresión y la crisis actual. Barcelona, $382 \mathrm{pp}$.

LANDES, D. (1999): La Riqueza y la Pobreza de las Naciones. Ed, Crítica, Barcelona, 599 pp.

LEVY, J. (Dir.) (2008): L'Invention du Monde: une géographie de la mondialisation. Presses de Sciences-Po, París, 408 pp.

LÓPEZ-RODRÍGUEZ, J. y FAIÑA, A. (2007): "Regional Wage Disparities in Europe: what rol for market acces?". Investigaciones Regionales, $\mathrm{n}^{\circ}$ 11, pp. 5-24.

MANZANERA E. y AURIOLES, J., (2004): Economía y Sociedad andaluza: análisis avanzado de las causas del desarrollo relativo. Centro de Estudios Andaluces, Sevilla, 145 pp.

MARCHENA, M.J. (2007): La Imagen Geográfica de Andalucía. Rd editores, Sevilla, 259 pp.

MARCHENA, M.J. (2015): "Best-Sellers" en Economía, una lectura desde la Geografía Económica". Revista de Estudios Andaluces, nº 32 (1), pp. 22-48.

MÁRQUEZ RAMAJO, J. y HEWINGS, G.J.D. (2011): "Public Capital and Regional Economic Growth: a SVAR Approach for the Spanish Regions". Investigaciones Regionales, , $\mathrm{n}^{\circ}$ 21, pp. 199-224.

MARTÍN, M.A. (2016): "La Economía en la Encrucijada”, en Informe CEA 2015, Sevilla, pp. 84-96. 
MASON, P. (2016): Postcapitalismo, hacia un nuevo futuro. Ed. Paidós, Madrid, 432 pp.

McCANN, P. (2015): The Regional and Urban Policy of the European Union. Elgar, Londres, $304 \mathrm{pp}$.

MORENO, M., RENART, M. y VIDAL, J.A. (2012): "Política Regional Europea: análisis de los informes de gestión de los Fondos Estructurales 2000-2006”. Investigaciones Regionales, $\mathrm{n}^{\circ} 22$, pp. 5-34.

NADAL, J. (Dir.) (2003): Atlas de la Industrialización de España 1750-2000. Fundación BBVA y Crítica, Barcelona, $662 \mathrm{pp}$.

PÉREZ-MALLAINA, E. (2010): Andalucía y el dominio de los espacios oceánicos. La organización de la Carrera de Indias en el siglo XVI. Corporación Tecnológica de Andalucía, Sevilla, 206 pp.

PIKETTY, T. (2013): Le capital au XXI Siècle. Seuil, París, 969 pp.

POLÈSE, M. y RUBIERA, F. (2009): Economía urbana y regional. Introducción a la Geografía económica. Cívitas Ediciones, Madrid, $310 \mathrm{pp}$.

RAMONET, I. (2011): Informe sobre la Globalización, en Le Monde Diplomatique, $\mathrm{n}^{\circ} 4$, Madrid, $126 \mathrm{pp}$.

REINHART, C. y ROGOFF, C. (2011): Esta vez es distinto: ocho siglos de necedad financiera. Fondo de Cultura Económica, 470 pp.

RETAILlÉ, D. (Dir.) (2010): La Mondialisation. Ed. Nathan, París, 382, pp.

RIFKIN, J. (2014): La sociedad de coste marginal cero: el internet de las cosas, los bienes comunes y el eclipse del capitalismo. Ed. Paidós, Madrid, 464 pp.

RUIZ, G. (2008): "Una visión general sobre el modelo de crecimiento chino y sus implicaciones para la economía global". Revista del Instituto de Estudios Económicos, $\mathrm{n}^{\mathrm{o}}$ 1, pp. 139-183.

SÁNCHEZ-SAUS, R. (2016): Al-Andalus y la Cruz. Ed. Stella Maris, Sevilla, pp. 522.

SASSEN, S. (2009): Una sociología de la globalización. Katz Barpal Editores, Madrid, 308 pp.

SCHULER, J.C. (2010): Mapping of the World. Ed. Place des Victoires, París, 383 pp.

SKIDELSKY, R. (2009): El regreso de Keynes. Ed, Crítica, Barcelona, 302 pp.

SOKOL, M. (2011): Economic Geographies of Globalisation. Elgar, Londres, 224 pp.

STIGLITZ, J. (2002): El malestar de la Globalización. Taurus, Madrid, 314 pp.

SUÁREZ DE VIVERO, J.L. (2014): "Changing maritime scenarios. The Geopolitical dimensión of the EU Atlantic Strategy". Marine Policy, no 48, pp. 59-72.

TERCEIRO, J. (2009): Economía del cambio climático. Taurus, Madrid, 140 pp.

TORIBIO, J.J. (2003): Globalización, Desarrollo y Pobreza. Círculo de Empresarios, Monografía $\mathrm{n}^{\mathrm{o}} 12$, Madrid, $217 \mathrm{pp}$.

VALLÉS, J., (2003): "La financiación pública de la economía andaluza". Administración de Andalucía: revista andaluza de administración pública, $\mathrm{n}^{\circ} 49$, pp. 25-58.

VÁZQUEZ, A. (2007): "Desarrollo endógeno, Teorías y políticas de desarrollo territorial”. Investigaciones Regionales, $\mathrm{n}^{\mathrm{o}} 11$, pp. 183-210.

WAHAB, E. y COOPER, CH. (Eds.) (2001): Tourism in the age of Globalization. Routledge, Londres, $259 \mathrm{pp}$. 